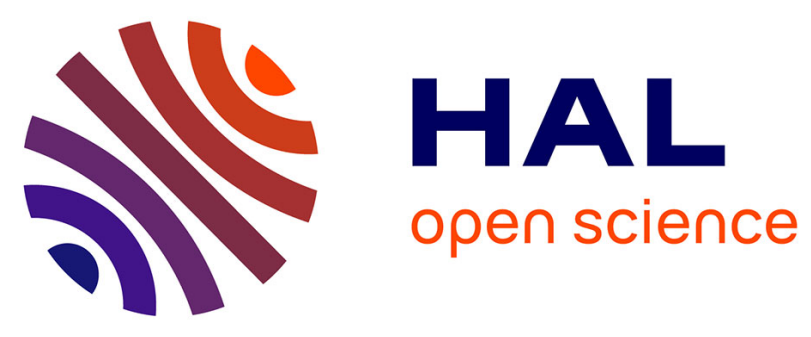

\title{
Understanding bat-habitat associations and the effects of 2 monitoring on long-term roost success using a volunteer dataset
}

Laurent Arthur, Michèle Lemaire, Léa Dufrêne, Isabelle Le Viol, Jean

François Julien, Christian Kerbiriou

\section{To cite this version:}

Laurent Arthur, Michèle Lemaire, Léa Dufrêne, Isabelle Le Viol, Jean François Julien, et al.. Understanding bat-habitat associations and the effects of 2 monitoring on long-term roost success using a volunteer dataset: Habitat selection inferred by distribution of breeding colonies. Acta Chiropterologica, 2014, 16 (2), pp.397-411. 10.3161/150811014X687350 . hal-02554599

\author{
HAL Id: hal-02554599 \\ https://hal.science/hal-02554599
}

Submitted on 26 Apr 2020

HAL is a multi-disciplinary open access archive for the deposit and dissemination of scientific research documents, whether they are published or not. The documents may come from teaching and research institutions in France or abroad, or from public or private research centers.
L'archive ouverte pluridisciplinaire HAL, est destinée au dépôt et à la diffusion de documents scientifiques de niveau recherche, publiés ou non, émanant des établissements d'enseignement et de recherche français ou étrangers, des laboratoires publics ou privés. 
1 Title:

2 Understanding bat-habitat associations and the effects of 3 monitoring on long-term roost success using a volunteer dataset

4

5 Running title:

6 Habitat selection inferred by distribution of breeding colonies

7

Laurent Arthur ${ }^{1}$, Michèle Lemaire ${ }^{1}$, Léa Dufrêne ${ }^{2}$, Isabelle Le Viol ${ }^{2}$, Jean François Julien², Christian Kerbiriou ${ }^{2}$

${ }^{1}$ Muséum d'histoire naturelle de Bourges, Les Rives d'Auron, Allée René Ménard, 18000 Bourges

${ }^{2}$ Conservation des Espèces, Restauration et Suivi des Populations - UMR 7204 MNHN-CNRSUPMC, 55 rue Buffon, 75005 Paris, France.

Corresponding author:

Christian KERBIRIOU

Muséum National d'Histoire Naturelle

UMR 7204 MNHN-CNRS-UPMC, 55 rue Buffon, 75005 Paris, France

Tel. [+0033] 1407938 31; Fax. [+0033] 140793835

E-mail: kerbiriou@mnhn.fr 


\section{Abstract (244 words)}

In gregarious species, the choice of colony location is especially crucial as the costs associated with breeding near conspecifics are important and the quality of breeding patch is known to affect individual fitness. Consequently one could expect robust decision-making rules regarding colony location. The conceptual framework of animal aggregation with regards to habitat selection emphasizes that the presence and success of conspecifics are cues to habitat selection. Based on this, we explored how the distribution of breeding colonies could inform us about how habitat selection operates in bats. The data set we used was provided by a volunteer network whose first aim is to advise citizens facing bats in distress or bats in their homes. The dataset contained information on the locations of 105 serotine (Eptesicus serotinus) breeding colonies in a French region primarily dominated by an agricultural landscape. The methodology used for calculating habitat availability was based on the comparison of habitats surrounding serotine colonies to habitats surrounding random points. We found that serotine bats positively select pastoral and aquatic habitats regardless of the comparison used. The strong correlation between our results and those obtained with radio-tracking or acoustic methods underlines the robustness of this spatial distribution approach. The analysis of the history of the serotine's colonies over a period of nearly 20 years underlined that when attics are restored by the owners without the help of the bat rescue network, the probability of a departure of colony is greater. In addition, monitoring reduces the occurrence of an unfriendly building restoration.

\section{Key words}

Habitat selection; distribution of colonies, local wildlife rescue networks; protection of above ground roots; Eptesicus serotinus; 


\section{Introduction}

Although legally protected in European countries through national or European laws (Council Directive 1992, Convention on Migratory Species (CMS 1985-2008), and Agreement on the conservation of Populations of European Bats), many European bats are endangered throughout much of their range (IUCN 2011). Numerous causes of this decline have been identified and include the availability of suitable foraging habitats (Walsh and Harris 1996, Kunz and Fenton 2003), agricultural practices that use toxic pesticides (Dunsmore et al. 1974, Swanepoel et al. 1999, Wickramasinghe et al. 2004), emerging infectious diseases (Frick et al. 2010, Puechmaille et al. 2011), and roost destruction and disturbance (MitchellJones et al. 2007). However, land use changes are often considered to be the principal cause of population decline in many bat species (Battersby 2010). The life history of bats is characterized by low fecundity and high longevity, and this K-strategy has been selected in a stable environment. Thus, bats are particularly vulnerable to environmental changes that lead to reduced demographic parameter values (Walsh and Harris 1996, Kunz and Fenton 2003). Therefore, an accurate description of the habitat requirements of threatened species, such as the bat, is a key part of conservation management (Walsh and Harris 1996).

The great majority of studies dealing with habitat preferences have been based on intensive protocols, such as radio-tracking (Robinson and Stebbings 1997, Goiti et al. 2003, DavidsonWatts et al. 2006, Flaquer et al. 2008). These methods often involve animal handling, such as capture during mist-net sessions, which can be controversial approaches when species are endangered and/or sensitive to disturbance. This is particularly the case for bats (Punt 1970, Dietz et al. 2006). In addition, these studies are often limited in space and time and involve a restricted number of individuals (Boughey et al. 2011). Complementary acoustic detection methods have been developed to describe foraging habitats (Carmel and Safriel 1998, Shiel and Fairley 1998, Rainho 2007). However, despite the quality information they produce, these two approaches (radio-tracking and acoustic) are time-consuming and require highly qualified people.

Due to the awareness of biodiversity loss, there is a pressing need for amateur naturalist volunteers to participate in data collection for biodiversity monitoring programs in Europe (Bell et al. 2008). Thanks to citizen scientists, studies can be carried out despite small budgets. Thus, the conservation initiatives and biodiversity studies carried out each year are numerous (Henry et al. 2008), while the budgets for biodiversity conservation are scattered and scarce. We need to better exploit the information contained in studies and field conservation experiences (Sutherland et al. 2004) and judge the effectiveness of conservation interventions in different contexts to ensure that the scarce funds go as far as possible toward improving our knowledge of the function of biodiversity to achieve conservation outcomes (Ferraro and Pattanayak 2006).

To date, the studies investigating roost data have dealt with roost characteristics, such as the height of roost openings above ground level (Simon et al. 2004), exposure (Simon et al. 2004), external or internal temperature (Churchill 1991, Mitchel-Jones et al. 2007), or hygrometric conditions (Hall 1982). These works were primarily conducted with the aim of identifying potential roost features and thus developing efficient conservation programs, such as physical protection measures (Mitchel-Jones et al. 2007), the restoration of roosts during the restoration of buildings or even the creation of new roosting opportunities (Marnell and Presetnik 2010). Surprisingly, however, very few studies have attempted to analyze spatial distribution data with the aim of identifying how habitat selection operates in 
bats' choice of roost (Lumsdem et al. 2002, Boughey et al. 2011, Nicholls and Racey 2011). The main reason for the lack of research on this topic is most likely related to the fact that, without a doubt, the choice of breeding site is primarily based on intrinsic characteristics (e.g., ease of access, temperature, luminosity, humidity, and so on). In addition to this, many species are highly philopatric (Bogdanowicz et al. 2013); thus, one could expect that bats will return to the same breeding site year after year even if the surrounding landscape suffers some changes. However, there are important costs associated with breeding in a colony such as the increased probability of transmission of parasites (Brown and Bomberger 1996) or diseases (Frick et al. 2010), the competition for space, food and mates. Thus, benefits must exist and must at least balance the cost (for more details, see Danchin and Wagner 1997). Thus, several authors have analyzed colonial species strategies in the framework of habitat selection (Doligez et al. 2003). Because the choice of a breeding patch affects individual fitness (i.e., survival and reproductive success), one could expect robust decisionmaking rules. Numerous theoretical, experimental and empirical studies (Danchin and Wagner 1997) have found that for colonial species, the presence and success of conspecifics are cues to habitat selection. For species that have a large number of sites available for reproduction, such as species able to use man-made aboveground structures, we hypothesize that we can detect how habitat selection operates using the spatial distribution of roosts. In contrast, exclusive cave-dwelling species potentially have much lower roost availability; thus, they most likely cannot afford to choose the roost by its surrounding habitat because it is likely a secondary endpoint compared to intrinsic characteristics of the site.

Here, we explored how the breeding colony distribution of a species using over-ground roosts (such as attic of house or church) could inform us of how habitat selection operates We used habitat variables that are available at the European level (Corine Land Cover 2000) and breeding colony data that was provided by a network of local bat rescue volunteers, with the aim of proposing a simple method with a high potential for generalization. Although the primary purpose of these associations is to assist and rehabilitate injured or orphaned bats, the identifying the location of breeding colonies is a natural output of such volunteer network. Many non-governmental nature conservation associations aim to help every citizen facing bat-related issues such as the discovery of a colony in their home and exist in many European states (see Mitchell-Jones et al. 2007, Marnell and Presetnik 2010, Boughey et al. 2011).

We used a dataset of serotine bat (Eptesicus serotinus) breeding colonies to explore how their distribution could inform us about habitat selection by this species. Maternity colonies of serotine bats are known to inhabit large roof spaces (Simon et al. 2004, Harbusch and Racey 2006, Vos et al. 2007). This data set was provided by a regional volunteer network. We studied the environment surrounding serotine breeding colonies in a 7,300 $\mathrm{km}^{2}$ French agricultural landscape and compared it to habitats surrounding randomly selected points. In addition, we assess the effectiveness of this monitoring in terms of serotine roost conservation.

\section{Material and Methods}

\section{Study areas}


The Museum of Bourges ( $L A$ and $\mathrm{ML}$ ) coordinated the inventory of bat colonies in the Cher from 1988 to 2009 . The Cher is an administrative region $\left(7300 \mathrm{~km}^{2}\right)$ in the centre of France (Fig. 1) that is primarily dominated by two contrasting agricultural practices: large patches of arable land (44\% of the total Cher area, average patch size: $5.1 \mathrm{~km}^{2} \pm 2.3 \mathrm{~km}^{2}$ ) and small patches of pasture ( $23 \%$ of the total Cher area, average patch size: $2.7 \mathrm{~km}^{2} \pm 1.2 \mathrm{~km}^{2}$ ). Forest covers $21 \%$ of the Cher's total surface (average patch: $1.9 \mathrm{~km}^{2} \pm 0.7 \mathrm{~km}^{2}$ ) (sources: Corine Land Cover 2000).

\section{Data collection}

\section{Volunteer's network}

The Museum of Bourges coordinates a network of volunteers who work on bat surveys and the local bat rescue network of this region. All volunteers were trained in the identification of bats from one of the co-authors (L.A. and M.L., co-director of the Museum of Bourges), and in addition, the vast majority of sites have been visited in the first year of their discovery by the two co-authors. This French network for bat rescue allows citizens to contact a bat expert in their region by calling a unique telephone number when they have question about bats. For example, when someone finds a bat in distress, discovers a bat colony in his home, or decides to restore a home and suspects that some bats are living here, an expert may provide legal information on bat protection status or solutions for home restoration that allow the sustainable maintenance of the bat colony. These experts often conduct private home visits and thus discover a breeding colony (Réseau SOS Chauve-souris 2011). Such networks also exist in many European countries (Marnell and Presetnik 2010). Most of the time, when a permanent relationship is established with the owner, bat colonies are secured and surveys are performed. In the Cher, this 22-year coordination has supported the development of an impressive database that contains 724 localized breeding colonies for 14 species. Because the aim of this study was to investigate habitat selection, we only considered breeding roosts.

\section{Serotine roosts}

Serotine bats primarily choose buildings as breeding sites (Schmidt 2002; Dietz et al. 2007). The database contains 105 Serotine bat colonies, $96 \%$ of which are located in attics, with the others located in bridges, in trees, in flues or behind shutters. The yearly rate of visit is $0.36 \pm$ $0.02 \mathrm{SE}$ (i.e., on average, a colony is visited every 3 years). We did not consider colony shifts from one house to another house (in the same village, for example) less than $1 \mathrm{~km}$ (average $300 \mathrm{~m}$ ) away as supplementary colonies. The shift of a colony from one roost to another occurred 6 times in the study period (1988-2009). Simon et al. (2004) also noticed small movements of breeding colonies.

\section{Constitution of the dataset and evaluation of potential bias}

Our dataset does not come from a systematic inventory but from opportunistic observations collected over a long period; thus, in our first step, we explored how the database (observations of colonies - locality and date, already known or new colonies) was built up over the years with the aim of evaluating potential bias. We used linear modelling to test the 
trends of discovery of new colonies ("cumulated number of colonies" as the response variable) along "years" (the explicative variable). We also used a Generalized Additive Model (GAM, Hastie and Tibshirani 1990; R package mgcv) to test the existence of non-linear effects of the yearly trend of new colonies in the database, with "years" as an explicative smoothed variable. As a second step, we assessed whether there were spatial and temporal biases in the implementation of this database. We tested if the discovery of a number of new colonies among regions (the study areas was split in 4 equal areas) was similar among periods (the study period was split in four periods: 1988-1993, 1993-1998, 1999-2003, 20042009) using a Chi-squared contingency table.

\section{Habitat selection analyses}

Before investigating the links between serotine habitat selection information and the spatial distribution of colonies, we tested the normality of colony distribution using the simple approach proposed by Clark and Evans (1954), which compares the expected mean distance to the nearest neighbor to the observed mean nearest neighbor distance.

We then tested the existence of a habitat selection process by comparing the habitat available in the study area and the habitat surrounding serotine breeding colonies $(n=105)$. With the aim of evaluating habitat availability, we inventoried habitats surrounding 105 random points used as pseudo-absence (using the random point function in ArcGis 9) by following the approaches of Jiguet and Villarubias (2004) and Boughey et al. (2011). Among these random points, we selected 105 points that included at least one hamlet or building in their $2 \mathrm{~km}^{2}$ buffer to attempt to account for serotine colony installation requirements (see Supplementary material - Appendix S1). No obvious bias was detected in the habitat area distribution of the random point data set and global habitat proportion in the Cher region (Kolmogorov-Smirnov test $D=0.36, p$-value $=0.078$ ). According to Phillips et al. (2009) we developed an alternative approach based on a target background approach for designing our pseudo absences: we used roost site locations of a species (Pipistrellus pipistrellus) which roosts in similar structures (data provide from the same data set than $E$. serotinus). Among the 411 breeding colonies of Pipistrellus pipistrellus (see Supplementary material - Appendix S1) we used 105 roosts as pseudo absences. These two species, even if they were not in mixed colonies in our case, are known to have very similar roost requirements (Simon et al. 2004; Dietz et al. 2007; Arthur and Lemaire 2009; Marnell and Presetnik 2010).

\section{Choice of buffer dimension}

The choice of the buffer size is an important statement; indeed, with a buffer size that is too small, the buffer may consider only a small part of the space that is potentially used by the individual of the colony. Conversely, with a buffer size that is too large, we may include many areas that are not used for foraging by breeders because of the distance to the colony. To select a buffer size that is ecologically practical, we relied on telemetry studies that were already conducted on this species. Radio-telemetry from serotine studies indicates that the distance between the breeding colony and foraging areas could reach $11.5 \mathrm{~km}$ (Degn 1983, Perez and Ibanez 1991, Diehl 1994, Weidner 1995, Catto et al. 1996, Robinson and Stebbings 1997, Lubeley and Bohle 2001), but the mean distance from roost to foraging areas ranges between 1.2 and 3.6 km (Hübner 1991, Dense 1992, Robinson and Stebbings 1997, Kervyn et al. 1998, Lubeley and Bohle 2001, Harbusch 2002, Simon et al. 2004). Thus, the home range 
of individually radio-tracked serotines was found to vary between $1.61 \mathrm{~km}^{2}$ and $17.05 \mathrm{~km}^{2}$ (Perez and Ibanez 1991) and $0.16 \mathrm{~km}^{2}$ to $47.58 \mathrm{~km}^{2}$ (Robinson and Stebbings 1997). The size of the home range per colony also varies considerably, ranging from $>2 \mathrm{~km}^{2}$ in the study carried out by Degn (1983) to $9.4 \mathrm{~km}^{2}$ (Rosenau 2001), $16 \mathrm{~km}^{2}$ (Diehl 1994), $26 \mathrm{~km}^{2}$ (Harbusch 2002) and $19 \mathrm{~km}^{2}$ for the core area of the colony in Robinson and Stebbings's study (1997). Thus, we chose a radius of $2 \mathrm{~km}$ around colonies or random points, which corresponded to an approximately $13 \mathrm{~km}^{2}$ area surrounding the colonies.

\section{Choice of habitat variables studied}

In addition to testing how habitat selection operates using the spatial distribution of roosts, we also wanted to assess the potential to generalize such a study. This is the reason why we used habitat data standardized at a large scale and with free access such as the Corine Land Cover (2000), even if such spatial information is considered relatively coarse. Hereafter, we use the habitat names used in the Corine Land Cover classification. Among the 25 habitat classes present in the Cher region, we selected the 18 most important habitats: those that had areas that represent more than $5 \%$ of the territory (see Figure 2). According to the resolution scale of the geographic information layer that we used (Corine Land Cover, CLC), the changes of land use can be considered to be minor during the study period (land cover flows in the studied region less affected than 1\% of land cover, source: 1992-2006 Land Cover Flows, http://www.eea.europa.eu).

As underlined by several studies, bats in general and Serotines in particular select linear elements of landscape within their foraging home range (Robinson and Stebbings 1997, Verboom and Huitema 1997, Waters et al. 1999, Russ and Montgomery 2002, Smith and Racey 2008). Therefore, we also assessed the length of forest edge and the length of rivers in the $2 \mathrm{~km}^{2}$ buffer areas in addition to habitat areas.

As we studied the breeding colonies, we expected a great sensitivity to the distance between the colony and foraging habitat in the serotines. The distance clearly appears to be an energetic constraint for breeding bats that must balance their night time budget between foraging in the landscape and feeding their young in the colony (Kunz and Fenton 2003). Therefore, we also included the distance to the nearest wood, pasture, and river in our analysis and the number of the confluence of two rivers within the buffer. So, in total, for each buffer, we have 24 variables: 18 variables that are surfaces of habitats (CLC class, m2), 3 variables are distances to habitat (pasture, river, wood), 2 variables that are linear densities (edge forest and river, $\mathrm{m}$ ) and 1 variable that is the number of river confluences.

\section{Statistical analysis}

We tested differences in habitat distribution between the surroundings of serotine colonies and the surroundings of random points using Generalized Linear Models (GLM). According to the nature of our response variable (presence/pseudo-absence), we used a binomial error distribution with logit link. Our explicative variables were habitat areas present in the $2 \mathrm{~km}^{2}$ buffer (areas were log transformed). According to numerous correlations between habitats (Spearman rho $>0.5$ ), such as the negative correlation between arable land and broad-leafed forest (see Supplementary material - Appendix S2), we analyzed the differences in habitat distribution between Serotine colonies and random points, habitat by habitat (i.e., 18 models), thus avoiding multi-colinearity problems. To account for spatial autocorrelation, we 
added an autocovariate (i.e., a distance-weighted function of neighboring response values; Dormann et al. 2007, Penone et al., 2013) with the autocov dist function in R (package spdep, Roger Bivand). Our statistical models were structured in the following way: [Presence/pseudo-absence] Habitat ${ }_{i}+$ autocovariate, where ${ }_{i}$ is one of the 18 selected habitat. The results were expressed using a F-test and accounting for over-dispersion by following the Faraway 2006 and Crawley 2009 approaches.

Beyond the identification of differences in habitat distribution between the surroundings of serotine colonies and the surroundings of random points, we tried to assess which differences are the most significant. In this second step, we simultaneously took into account all habitat variables in the analysis using Hierarchical Partitioning (HP, R package hier.part, Chris Walsh), a multiple regression analytical method that allow us to identify the most likely causal factors while alleviating multicollinearity problems (Mac Nally 2000). Based on Olea et al. (2010), commenting on Hierarchical Partitioning usage limits, we limited this hierarchical partitioning to the 9 most important habitats.

In a third step, because the choice of buffer size is an important statement for this study, we evaluated whether the scale choice based on the ecology of the species was efficient and because the species responds to their environment on a range of scales (Boughey et al 2011), we performed a multiscale habitat association study using GLM. We used the same response variable (presence/pseudo-absence of Serotine roost) and a restricted set of habitat variables chosen to be significant for discriminating Serotine roosts and random points (results of the two previous steps) without exhibiting important correlation (see Supplementary material - Appendix S2). Our statistical models were structured in the following way:

[Presence/pseudo-absence] Habitat ${ }_{i}+$ Habitat $_{j}+$ Habitat $_{k}+\ldots$, autocovariate

We ran these models with different buffer sizes, from a radius of $100 \mathrm{~m}$ around colonies or random points to $8000 \mathrm{~m}$. Habitat areas were expressed as a percentage of areas within the buffer. As in the first step, we included an autocovariate function and used a binomial error distribution with logit link. To adjust the effect of each variable to the effects of other variables, test values were expressed using type-II analysis-of-variance ( $R$, package car, John Fox). Type II tests are calculated according to the principle of marginality, each term is tested after all others (Crawley 2009), and we take into account over-dispersion.

\section{Effectiveness of this monitoring in terms of serotine roost conservation}

Such networks involving citizen-landowners have resulted in the establishment of frequent and permanent relationships with the owner. Hereafter, we assess the effectiveness of this relationship in terms of the sustainability of serotine roosts in the long term (when landowners plan to work in their attics or the renovation of heritage buildings, etc.).

Using Generalized Linear Models (GLM with binomial error distribution), we attempt to identify which factor could influence the sustainability of serotine roosts: changes in facilities (type of facilities were ranked from soft to important in four classes (i.e., from changes some tiles to the total re-roofing), and a fifth class in cases where there is a deliberate attempt to remove the colony) that plans and designs the work of building restoration (Museum of Bourges vs. landowners) and the year and the size of the serotine population. We used the database of the history of serotine colonies $(n=105)$ over a period of 22 years, including 48 
events of work in buildings sheltering serotine colonies. Test values were expressed using type-II analysis-of-variance ( $R$, package car). All of the analyses were computed with R software (R Development Core Team 2010).

\section{Results}

\section{Evaluation of spatial and temporal biases in the establishment of the database}

During the colony inventory period (1988-2009), we detect a significant continuous annual growth in the inventoried serotine colonies (an addition of 5 colonies/year, $\mathrm{R}^{2}=0.99, F_{1,20}=$ 2581.8, $P<0.0001$, see supplementary material 1$)$. No non-linear effects were detected (Generalized Additive Model, $F_{1,20}=1.2, P=0.33$, see Supplementary material - Appendix S3). To evaluate the possibility of a bias in the accumulation of space and time data, we split the Cher region into four equal areas and split the time series into periods of 4 years. We did not detect any obvious bias in the location of new colonies across any time period (Chi sq = $10.9, d f=12, P=0.54)$.

\section{Habitat selection analyses}

The density of the serotine colonies observed in the study area was $0.01 / \mathrm{km}^{2}$. The comparison of the actual mean nearest neighbor distance between Serotine colonies $(4.1 \mathrm{~km}$ $\pm 0.3 \mathrm{~km}$ ) and the expected mean distance to the nearest neighbor ( $D=\sqrt{ }$ colony density $/ 2=$ $42.7 \mathrm{Km}$ ) indicated a non-spatial randomness of colonies and a clear aggregation pattern. Thus, it is legitimate to inquire whether this aggregated distribution is related to the distribution of some habitats.

Thus, we first explored habitat selection by comparisons with random points, finding that serotine bats appear to positively select pastures $(P<0.001)$ and areas near streams or water bodies $(P=0.002)$ while avoiding heterogeneous agricultural areas $(P<0.001)$, which is land principally occupied by agriculture areas with significant areas of natural vegetation, broadleafed forests $(P=0.028)$, transitional woodland-shrub $(P=0.034)$, and water bodies $(P=0.002)$ (Fig. 2, see Supplementary Material Appendix S3). Undeniably, the greatest difference comes from pasture selection (Fig. 2). In addition, serotine roosts are closer to pastures $(P<0.001$; average: $304 \mathrm{~m} \pm 38 \mathrm{SE})$ and rivers $(P<0.001$; average: $461 \mathrm{~m} \pm 45 \mathrm{~m})$ than are random points $(1096 \mathrm{~m} \pm 129 \mathrm{~m}$ and $1054 \mathrm{~m} \pm 94 \mathrm{~m})$. Serotine roosts are also located in areas with greater river density $(P<0.001)$ and higher river confluence density $(P<0.001)$ (greater from a factor: one point six and one point eight, see Supplementary material - Appendix S4) than random points. However, no significant differences in the distance to nearest wood or forest edge density were detected.

In addition, comparison between habitats surrounding serotine roosts with those surrounding random points assessed with Hierarchical Partitioning analysis showed that the presence of pastures is the most likely causal factor (Fig. 3).

Similar significant results were obtained with pseudo-absence point based on $P$. pipistrellus roosts: for example serotine bats appear to positively select pastures and areas near streams or water bodies and to avoid heterogeneous agricultural areas and broad-leafed forests. The two main differences are the positive selection of arable land and the avoidance of discontinuous artificial surfaces (See Supplementary material - Appendix S5). 
Hierarchical Partitioning analysis for landscape structure showed that the distance to the nearest pasture, the distance to the nearest river and the river density were the most likely causal factors between habitats surrounding serotine roosts compared to random points. With the aim of assessing the joint effects of the major variables of interest and the influence of the size of the buffer, we performed linear models, including simultaneously considering Pasture (H231), Heterogeneous agricultural areas (H242), Land principally occupied by agriculture with significant areas of natural vegetation $(\mathrm{H} 243)$ and river density as explicative variables. These four variables exhibit no obvious correlation (see Supplementary material - Appendix S2). We found that serotine bats appear to positively select pastures whatever the scale considered, whereas habitat $\mathrm{H} 243$ did not appear as a significant variable whatever the scale considered (Table 1). Habitat $\mathrm{H} 242$ and river density appeared to be scale dependent: $\mathrm{H} 242$ exhibit a slight trend towards being significant on a small scale, whereas river density appeared only significant at a large scale (Table 1). According to the AIC value, the best model was obtained with a buffer size of $2000 \mathrm{~m}$.

\section{Effectiveness of this monitoring in terms of serotine roost conservation.}

The sustainability of serotine roosts were negatively influence by changes in facilities carried out by landowners without agreement with the Museum of Bourges (GLM $\chi^{2}=12.450$, d.f. $=1$, $P<0.001, b=-5.318$ ), whereas facilities designed by the Museum of Bourges team or in accordance with it did not have a significant effect on the persistence or departure of colonies (GLM $\left.\chi^{2}=0.024, d . f .=1, P=0.876, B=0.193\right)$. We did not detect any significant effect of type of facilities (GLM $\chi^{2}=0.024$, d.f. $=1, P=0.530, B=-0.294$ ). In addition, we also detected a significant effect of the year (GLM $\left.\chi^{2}=36.860, d . f .=22, P=0.025\right)$ and the size of the serotine population: larger populations were more stable ( $G L M \chi^{2}=16.088, d . f .=1, P<0.001, b=1.088$ ). Finally, we observed that over time, building restorations carried out by landowners without agreement of the Museum of Bourges significantly decreased (GLM $\chi^{2}=7.947$, d.f. $=1$, $P=0.005$ ), whereas we did not detect any trend in the occurrence of building restoration carried out by the Museum of Bourges team or in accordance with it (GLM $\chi^{2}=2.178$, d.f. $=1$, $P=0.139$ ). This suggests that the stronger the link (in terms of year) between the museum and the owner of a building is, the more the likelihood of making arrangements that disrupt colonies decreases.

\section{Discussion}

\section{Habitat selection.}

This study clearly indicates that even species that are considered generalists (Kerbiriou et al. 2010, Regnery et al. 2013) with regards to the selection of foraging habitat make obvious choices for the location of their breeding colonies. This choice takes the nature of the surrounding habitat into account. Choosing a specific habitat surrounding colonies is even more unexpected for serotine bats, as this species is known to manage quite a long distance between foraging habitats and breeding colonies $(11.5 \mathrm{~km})$.

Land use in the Cher region has resulted in a landscape structure in which arable land is negatively correlated with pasture or forest (see Supplementary material - Appendix S2). 
Due to this spatial structure, it is possible to directly identify whether serotine bats make a positive selection for one habitat (such as pasture) or avoid another (such as arable land). Our study has identified pastures as the most selected habitat, covering on average $37 \%$ of the $2 \mathrm{~km}$ buffer around roosts. The majority of studies investigating serotine foraging habitats have made this observation (Catto et al. 1996, Robinson and Stebbings 1997, Kervyn, 2001). The study carried out by Boughey et al. (2011) showed a strong relationship between the probability of serotine roosts and the proportion of improved grassland. This affinity to agricultural land is underscored by the proportion of arable land neighboring the roosts ( $45 \%$ on average). However, arable land accounts for the majority of the land use cover of this region; thus, serotine bats appeared to select arable land slightly less frequently than random points. The observed pattern of aquatic habitat selection ( $\%$ of water stream cover, linear elements) around serotine roosts is in accordance with a large number of studies that have identified the importance of these habitats for serotine foraging activities (acoustic studies: Hübner 1991, Vaughan et al. 1997, Barataud 1998, Lustrat 2001, Ciechanowski 2002, Bartonicka et al. 2003, Russo and Jones 2003, Kanuch et al. 2006, Rainho 2007 or radio-tracking study: Simon et al. 2004; habitats surrounding roosts: Boughey et al. 2011).

A difference between our results and some previous studies (Barataud 1998, Lustrat 2001; Russo and Jones 2003, Rainho 2007) is the non-selection of forest habitat, particularly broadleaved woodland. Boughey et al. (2011) found a similar result in the UK. Again, it is interesting to consider the habitat surface present close $(2 \mathrm{~km})$ to serotine roosts: woodland is the third most abundant habitat and covers more than $13 \%$ of the area, so a plausible hypothesis is that the current amount of woodland surrounding roost is sufficient. This possibility explains why we did not detect any selection effect. A second minor difference is the non-selection of urban areas in our study. Due to the selection of roosts in buildings, the proportion of urban areas surrounding serotine roosts is not negligible (6\%). However, when comparing this proportion to the proportion of urban areas that surrounded random points, no significant difference could be detected, although some studies have found that foraging serotines choose this habitat (Barataud 1998, Gaisler et al. 1998, Bartonicka and Zukal 2003, Russo and Jones 2003, Rainho 2007).

\section{Conservation implications}

We found that for the E. serotinus, a species that has a large number of sites available for reproduction because of its ability to use man-made aboveground structures, roost are not distributed randomly. In addition to roost characteristic (not studied here), for their maternity roosts, serotine bats select landscapes with an important proportion of habitats known to be used for foraging (pastoral and aquatic habitats). This result converges with those found by Boughey et al. (2011) for P. pipistrellus, P. pygmaeus, Rhinolophus hipposideros, Eptesicus serotinus and Myotis nattereri (sensus lato), species that all selected roosts closer to broadleaved woodland than expected by chance. However, the protection of habitats surrounding maternity roosts is not regularly implemented in conservation measures: as an example, in France, most areas dedicated to bat conservation, such as natura2000 take into account underground cavities used for nesting sites without taking account the foraging range of the colony or its foraging habitat. Another French regulation called "Arrêté préfectoral de protection de biotope, French law of July 16, 1976", when implemented for bats, only protects the attic or the cavity in which the roost is located and 
again does not consider the hunting ground associated with the colony. For serotine bats, our results suggest that protection of the foraging habitat around the maternity roost should be considered at least within a radius of 2000 meters. In addition, conservation of this species should focus on pasture maintenance, particularly those close to rivers

\section{Evaluation of the proposed method.}

The strong convergence of our results with those obtained by radio-tracking or acoustic methods for the identification of the most selected habitats or relevant spatial scale, underlines the robustness of an approach that is based on the spatial distribution of roosts. Moreover, this approach also allows us to study the impact of the landscape structure and clarify some selection processes, such as forest vs. forest edges.

The existence of international biodiversity monitoring networks that are based on highly standardized protocols and have a staff of paid experts would be ideal for providing accurate knowledge of species requirements and population trends, among other things (Henry et al. 2008). Therefore, combining the output available from various approaches and ongoing monitoring initiatives is an optimal option. This requires the ability to integrate heterogeneous information on biodiversity, which appears to be more likely due to progress in meta-analysis methodology (Bengtson et al. 2005, Sutherland 2006, Henry et al. 2008). Thus, analysis of the environment surrounding roosts appears to be a complementary and promising approach for implementing knowledge of the habitat requirements of bats and, especially, for species that have a large number of sites available for reproduction. The species concerned may be those that regularly used man-made aboveground structures, such as Pipistrellus species, Plecotus species, Rhinolophus ferrumequinum, $R$. hipposideros, Barbastella barbastellus, Myotis daubentonii and Myotis myotis (Simon et al. 2004, Dietz et al. 2007, Arthur and Lemaire 2009, Marnell and Presetnik 2010). Furthermore, information on roost localization can be accurately gathered by a volunteer network, as in our study. Fortunately, such a volunteer network is also currently being developed in many countries (see Mitchell-Jones et al. 2007, Battersby 2010, Marnell and Presetnik 2010, Boughey et al. 2011). Public participation in scientific research is recognized as a promising approach to significantly help scientists address biodiversity issues (Bell et al. 2008, Couvet et al. 2008, Henry et al. 2008). It is likely that the use of data from a study dedicated to the systematic inventory of bat colonies in houses in a relatively large area, such as the Cher $\left(7300 \mathrm{~km}^{2}, 290\right.$ towns and villages, 313251 inhabitants), by a strictly professional organization would not have generated an unbiased distribution over time and space. If not for limited resources (financial and human), a professional organization would have planned this inventory effort, and the area most likely would have been surveyed sector by sector over time. Thus, the absence of an obvious spatio-temporal bias is likely linked to this volunteer network-based approach. The benefits of volunteer networks are numerous and not only limited to financial savings (Levrel et al. 2010), and these benefits include the fact that citizen monitoring systems are likely to have a high resilience (Couvet et al. 2008), which is the key to maintaining the network over time and thus provide an extended time-series (Battersby 2010) or large spatial coverage (Jaberg and Guisan 2001, Lepczyk et al. 2005). In addition, this network provides socially legitimate results that contribute to improving the relevance of results, aid in the identification of key biodiversity issues through discussions between citizens and scientists, and orient public policies and actions towards adaptive management (Couvet et al. 2008). 
Finally, such networks involving citizen-landowners have resulted in (i) gathering information

501

502

503

504

505

506

507

508

509

510

511

512

513

514

515

516

517

518

519

520

521

522

523

524

525

526

527

528

529

530

531

532

533

534

535

536

537

538

539

from private houses, where access is not easy and authorization demands are highly time consuming; (ii) better monitoring of bat colonies (such observations were noticed by Lepczyk (2005) in a bird survey that integrated citizen science); (iii) increasing the availability of a cost-effective data collection method that provides high quality data that are available for conservation biology investigations and actions, and (iv) establishing frequent and permanent relationships with the owner, which contributes to securing bat roosts: this relationship significantly decreased the building restoration carried out by landowners without an agreement with the local wildlife rescue networks, as these types of building restorations have been assessed to have a significant impact on the persistence of bat roosts.

\section{Acknowledgements}

We thank deeply volunteers involve for data collection and Julie Marmet for helpful comments on the manuscript.

\section{Literature cited.}

AgREEMENT ON THE CONSERVATION OF POPULATIONS OF EuROPEAN BATS. http://www.eurobats.org/documents/index.htm.

Arthur, L. and M. Lemaire. 2009. Les chauves-souris de France, Belgique, Luxembourg et Suisse. Biotope, Mèze, Muséum National d'Histoire Naturelle, Paris 544p.

BATTERSBY, J. 2010. Guidelines for surveillance and monitoring of European bats. EUROBATS Publication Series No. 5. UNEP / EUROBATS Secretariat, Bonn, Germany, 95 pp.

BARATAUD, M. 1998. Inventaire au détecteur d'ultrason des chiroptères fréquentant les zones d'altitude du nord du parc National du mercantour (Alpes, France). Le Rhinolophe, 13: 43-52.

BARTONICKA, T., and J. ZUKAL. 2003. Flight activity and habitat use of four bat species in a small town revealed by bat detectors. Folia Zoologica, 52: 155-166.

Bell, S., M., Marzano, J. Cent, H. Kobierska, D. Podjed, D. Vandzinskaite, H. Reinert, A. Armaitiene, M. GRODZIŃSKA-JURCZAK, and R. MURŠIČ. 2008. What counts? Volunteers and their organisations in the recording and monitoring of biodiversity. Biodiversity and Conservation, 17: 3443-3454.

Bengtsson, J., J. Ahnström, and A-C. Weibull. 2005. The effects of organic agriculture on biodiversity and abundance: a meta-analysis. Journal of Applied Ecology, 42: 261-269. 
Bogdanowicz W., G. Lesiński, M. SAdkowska-Todys, M. Gajewska, and R. RutKowski. 2013. Population Genetics and Bat Rabies: A Case Study of Eptesicus serotinus in Poland. Acta Chiropterologica, 15: 35-56.

BougheY, K.L, I.R., LAKE, K.A., HAYSOM, P.M., Dolman 2011. Effects of landscape-scale broadleaved woodland configuration and extent on roost location for six bat species across the UK. Biological Conservation, 144: 2300-2310

Brown, C. R., and M. B. Bomberger. 1996. Coloniality in the cliff swallow the effect of group size on social behavior, University of Chicago Press.

CARMEL, Y., and U. SAFRIEL.1998. Habitat use by bats in a Mediterranean ecosystem in IsraelConservation implications. Biological Conservation, 84: 245-250.

Catto, C., A. M., Hutson, P. A. Racey, and P. J. Stephenson. 1996. Foraging behaviour and habitat use of the serotine bat (Eptesicus serotinus) in southern England. Journal of Zoology (London), 238: 623-633.

CHURCHILL, S.K. 1991. Distribution, abundance and roost selection of the orange horeshoebat, Rhinonycteris aurantius a tropical cave-dweller. Wildlife Research, 18: 343-353.

CIECHANOWSKI, M. 2002. Community structure and activity of bats (Chiroptera) over different water bodies. Mammalian Biology, 67: 276-285.

CLARCK, P.J., and F.C. EVANS. 1954. Distance to nearest neighbor as a measure of spatial relationships in populations. Ecology, 35: 445-453.

CORINE LAND COVER, 2000. http://sia.eionet.europa.eu/CLC2000, assessed march 2010.

CMS, 1995-2008. Convention on migratory species of wild animals. Appendix II (as amended by the Conference of the Parties in 1985, 1988, 1991, 1994, 1997, 1999, 2002, 2005 and 2008) http://www.cms.int/.

COUNCIL DIRECTIVE, 1992. Council Directive 92/43/EEC of 21 May 1992. on the conservation of natural habitats and of wild fauna and flora-Annex II http://ec.europa.eu/environment/index_en.htm.

Couvet, D., F. Jiguet, R. Julliard, H. Levrel, and A. Teyssedre. 2008. Enhancing citizen contributions to biodiversity science and public policy. Interdisciplinary Science Reviews, 33: 95-103.

CRAWLEY, M.J. 2009. The R book. John Wiley and Sonc 942p. UK.

DANCHIN, E. and R. H. WAGNER. 1997. The evolution of coloniality: the emergence of new perspectives. Trend in Ecology and Evolution, 12: 342-347. 
DAVIDSON-WATtS I., S. WALLS, and G. JONES. 2006. Differential habitat selection by Pipistrellus pipistrellus and Pipistrellus pygmaeus identifies distinct conservation needs for cryptic species of echolocating bats. Biological Conservation, 133: 118-127.

DENSE, C. 1992. Telemetrische Untersuchungen zur Habitatnutzung und zum Aktivitätsmuster der Breitflügelfledermaus Eptesicus serotinus Schreber, 1774 im Osnabrücker Hügelland. PhD thesis, University of Osnabrück.

DEGN, H. J. 1983. Field activity of a colony of Serotine Bat (Eptesicus serotinus). Nyctalus, 1: 521-530.

DiEHL, D. A. 1994. Untersuchungen zur biologie der Breitflügelfledermaus in Hessen. In Die fledermause Hessen (AGFH), Verlag Manfred Hennecke, Remshalden-Buoch, pp: 128132.

DietZ, C., I. DietZ, T. IVANOva, and B. M. Siemers. 2006. Effects of forearm bands on horseshoe bats (Chiroptera: Rhinolophidae). Acta Chiropterologica, 8: 523-535.

Dietz, C., O. Von Helversen, and D. NiLl. 2007. Handbuch der Fledermäuse Europas. Stuttgart: Franckh-Kosmos-Naturfüher Verlargs

Doligez, B., C., CADET, E. DANCHIN, and T. Boulinier. 2003. When to use public information for breeding habitat selection? The role of environmental predictability and density dependence. Animal Behaviour, 66: 973-988.

Dormann, C., M. McPherson, J., B. Araújo, M., Bivand, R., Bolliger, J., Carl, G., G. Davies, R., Hirzel, A., Jetz, W., Daniel Kissling, W., Kühn, I., Ohlemüller, R., R. Peres-Neto, P., Reineking, B., SCHRÖDER, B., M. SCHURR, F. and WILSON, R. (2007), Methods to account for spatial autocorrelation in the analysis of species distributional data: a review. Ecography, 30: 609-628

DUNSMORE, J., L. S. HALL, and K. H. KOTTEK. 1974. DDT in the bent-winged bat in Australia. Search, 5: 110-111.

FARAWAY, J. J. 2006. Extending the linear model with R, generalized linear, mixed effects and nonparametric regression models. Chapman and Hall/CRC. 301p. USA.

Ferraro, P. J. and S. K. PATtANAYAK. 2006. Money for nothing? A call for empirical evaluation of biodiversity conservation investments. PloS Biology, 4: 482-488.

Flaquer, C., X. Puig-Montserrat, A. Burgas, and A. D. Russo. 2008. Habitat selection by Geoffroy's bats (Myotis emarginatus) in a rural Mediterranean landscape: implications for conservation. Acta Chiropterologica, 10: 61-67. 
Frick, W. F., J. F., Pollock, A. C. Hicks, K. E. Langwig, D. S. Reynolds, G. G. Turner, C. M. BUTCHKOSKI, and T. H. KUNZ. 2010. An emerging disease causes regional population collapse of a common North American bat species. Science, 5992: 679-682.

HALL, L. S. 1982. The effect of cave microclimate on winter roosting behaviour in the bat, Miniopterus schreibersii blepotis. Australian Journal of Ecology, 7: 129-136.

HARBUSCH, C. 2002. Aspects of the ecology of Serotine bats (Eptesicus serotinus, Schreber 1774) in contrasting landscapes in Southwest Germany and Luxembourg. PhD thesis, University of of Aberdeen.

HARBUSCH C., J.P., RACEY 2006. The sessile serotine: the influence of roost temperature on philopatry and reproductive phenology of Eptesicus serotinus (Schreber, 1774) (Mammalia: Chiroptera). Acta Chiropterologica 8(1):213-229.

HASTIE, T. J., and R. J. TIBSHIRANI. 1990. Generalized additive models. Chapman and Hall, London.

HÜBNER, I. 1991. Untersuchungen zur Lebensweise der Breitflügelfledermaus Eptesicus serotinus Schreber, 1774 in Hollingstedt/Schleswig Holstein. PhD thesis, University of Kiel.

Henry, P.Y., S. Lengyel, P. Nowicki, R. Julliard, J. Clobert, T. Čelik, B. Gruber, D. S. Schmeller, V. BABIJ, and K. HENLE. 2008. Integrating ongoing biodiversity monitoring: potential benefits and methods. Biodiversity and Conservation, 17: 3357-3382.

GAISLER, J., J. ZUKAL, Z. REHAK, and M. HOMOLKA. 1998. Habitat preference and flight activity of bats in a city. Journal of Zoology (London), 244: 439-445.

GoITI, U., I. GARIN, and J. ZABALA. 2003. Influence of habitat on the foraging behaviour of the Mediterranean horseshoe bat, Rhinolophus euryale. Acta chiropterologica, 5: 75-84.

IUCN. 2011. Red List of Threatened Species. Version 2011.1. http://www.iucnredlist.org.

JABERG, C., and A. GUISAN. 2001. Modelling the distribution of bats in relation to landscape structure in a temperate mountain environment. Journal of Applied Ecology, 38: 11691181.

Jiguet, F.,, and S. VilLARUBIAS. 2004. Satellite tracking of breeding black storks Ciconia nigra: new incomes for spatial conservation issues. Biological Conservation, 120: 153-160.

Kanuch, P., S. Danko, M. Celuch, A. Kristin, P. PJencak, S. Matis, and J. Smid. 2006. Relating bat species presence to habitat features in natural forests of Slovakia (Central Europe). Mammalian Biology, 73: 147-155. 
Kerbiriou, C., Y., BAS, L., Dufrêne, A., Robert, J.F., Julien 2010. Long term trends monitoring of bats, from biodiversity indicator production to species specialization assessment. Society for Conserv. Biol. - 24th Annual Meeting, 3 - 7 July, 2010, Edmonton, Alberta, Canada.

Kervyn, T., J. Brasseur, G. Motte, and R. Libois. 1998. Foraging and feeding ecology of the serotine bat Eptesicus serotinus. Bat Research News: 39, 84.

KUnz, T.H. and M. B. Fenton. 2003. Bat ecology Chicago, IL University of Chicago Press.

LEPCZYK, C.A. 2005. Integrating published data and citizen science to describe bird diversity across a landscape. Journal of Applied Ecology, 42: 672-677.

Levrel, H., B. Fontaine, P.y. Henry, F. Jiguet, R. Julliard, C. Kerbiriou, and D. Couvet. 2010. Balancing state and volunteer investment in biodiversity monitoring for the implementation of CBD indicators: A French example. Ecological Economics, 69: 15801586.

LUBELEY, S. and W. BOHLE. 2001. Zur Jagdhabitatnutzung der Breitflügelfledermaus (Eptesicus serotinus). In: Zotz, G. and Körner, C. Funktionelle Bedeutung von Biodiversität. Kurzfassungen der Beiträge zur 31. Jahrestagung der gesellschaft für ökologie in Basel vom 27.-31.8. 2001. Basel (Springer-Verlag) 32p.

LUMSDEN, L. F., A. F. BenNetT, J. E. SILINS. 2002. Location of roosts of the lesser long-eared bat Nyctophilus geoffroyi and Gould's wattled bat Chalinolobus gouldii in a fragmented landscape in south-earstern Australia. Biological Conservation, 106: 237-249.

LUSTRAT, P. 2001. Les territoires de chasse des chiroptères de la forêt de fontainebleau (France). Le Rhinolophe, 15: 167-173.

MAC NALLY, R. 2000. Regression and model building in conservation biology, biogeography and ecology: the distinction between and reconciliation of 'predictive' and 'explanatory' models. Biodiversity and Conservation, 9: 655-671.

MARnelL, F. and F. P. Presetnik. 2010. Protection of over ground roosts for bats (particularly roosts in buildings of cultural heritage importance). EUROBATS Publication Series No 4 (English version). UNEP/EUROBATS Secretariat, Bonn, Germany, 57pp.

Mitchell-Jones, A.J., Z. BIHARI, M. MASING, and L. RodRIGUeS. 2007. Protecting and managing underground sites for bats. EUROBATS Publication Series No. 2 (English version). UNEP / EUROBATS Secretariat, Bonn, Germany, 38 pp.

NiCHOLLS, B. and P. A. RACEY. 2011. Habitat selection as a mechanism of resource partitioning in two cryptic bat species Pipistrellus pipistrellus and Pipistrellus pygmaeus. Ecography, 29: 697-708. 
Penone C., Le Viol I., Pellissier V., Julien J-F., Bas Y., Kerbiriou C. 2013 Assessing anthropogenic pressures on Orthoptera communities using large scale acoustic monitoring. Conservation Biology 27: 979-987.

Phillips S.J., Dudik M., Elith J., Graham C.H., Lehmann A., Leathwick J., Ferrier S. 2009. Sample selection bias and presence-only distribution models: implications for background and pseudo-absence data. Ecological Applications 19: 181-197.

Puechmaille, S. J., W. Frick, T. H. Kunz, P. A. Racey, C. C. Voigt, G. Wibbelt, and E. C. Teeling. 2011. White-Nose Syndrome: is this emerging disease a threat to European bats? Trends in Ecology \& Evolution 26: 570-576.

Punt, A. 1970. Round table discussion on bat conservation. Proceeding of the Second International Bat Research Conference, 3-4.

R DeVelopment Core Team. 2010. R: a language and environment for statistical computing. $R$ Foundation for Statistical Computing, Vienna, Austria. http://www.r-project.org/.

RAINHO, A. 2007. Summer foraging habitats of bats in a Mediterranean region of the Iberian Peninsula. Acta Chiropterologica, 9 : 171-181.

Regnery B., D., Couvet, L., Kubarek, J.F., Julien, C., Kerbiriou 2013. Tree microhabitats as indicators of bird and bat communities in Mediterranean forests. Ecological Indicators $34: 221-230$.

RÉSEAU SOS CHAUVE-SOURIS, 2011. Http://www.museum-bourges.net/chauve-souris-un reseaud-aide-29.html.

Robinson, M.F., and R. E. Stebbings. 1997. Home range and habitat use by serotine bat, Eptesicus serotinus, in England. Journal of Zoology (London), 243: 117-136.

ROSENAU, S. 2001. Untersuchungen zur Quartiernutzung und Habitatnutzung der Breitflügelfledermaus Eptesicus serotinus (SCHREBER, 1774) im Berliner Stadtgebiet (Bezirk Spandau). - Diplomarbeit FU Berlin, $120 \mathrm{~S}$.

Russ, J. M., and W. I. Montgomery. 2002. Habitat associations of bats in Northern Ireland: implications for conservation. Biological conservation, 108: 49-58.

RUSSO, D., and G. JONES. 2003. Use of foraging habitats by bats in a Mediterranean area determined by acoustic surveys: conservation implications. Ecography, 26: 197-209.

SCHMIDT, C. 2002. The occurrence of bats in the town of Hoyerswerda. Przyroda sudetow zachodnich, 2: 71-78. 
SHIEL, C. B., and J. S. FAIRLEY. 1998. Activity of Leisler's Bat Nyctalus leisleri (Kuhl) in the Field in South-East County Wexford, as Revealed by a Bat Detector. Proceeding of the Royal Irish Acadademy, 98: 105-112.

SIMON, M., S. HÜTTENBÜGEL, and J. SMIT-VIERGUTZ. 2004. Ecology and conservation of bats in villages and town. Bundesamt für Naturschutz - Federal Agency for Nature Conservation.

SMITH, P. G., and, P. A. RACEY. 2008. Natterer's bats prefer foraging in broad-leaved woodland and river corridors. Journal of Zoology (London), 275: 314-322.

SteBbingS, R. 1988. The conservation of European bats. Christopher Helm, London, UK.

Sutherland, W.J., A.S. Pullin, P. M. Dolman, and T. M KNight. 2004. The need for evidencebased conservation, Trend in Ecology and Evolution, 19: 305-308.

SUtHeRLAND, W.J. 2006. Predicting the ecological consequences of environmental change: a review of the methods. Journal of Applied Ecology, 43: 599-616.

Swanepoel, R. E., P. A. Raceya, R. F. Shore, and J. R. Speakman. 1999. Energetic effects of sublethal exposure to lindane on pipistrelle bats (Pipistrellus pipistrellus) Environmental Pollution, 104: 169-177.

VAUGHAN, N., G. Jones, S. HARRIS. 1997. Identification of British bat species by multivariate analysis of echolocation call parameters. Bioacoustics, 7: 189-207.

Verboom, V., and H. Huitema. 1997. The importance of linear landscape elements for the Pipistrelle Pipistrellus pipistrellus and the serotine bat Eptesicus serotinus. Landscape Ecology, 12: 117-125.

Vos A.,, I., Kaipf A., Denzinger, A.D., Fooks, N., Johnson, T., Müller 2007. European bat lyssaviruses - an ecological enigma. Acta Chiropterologica 9(1):283-296

WALSH, A. L., and S. HARRIS. 1996. Foraging habitat preference of vespertilionid bats in Britain. Journal of Applied Ecology, 33: 508-518.

WATERS, D., G. JONES, and M. FURLONG. 1999. Foraging ecology of Leisler's bat (Nyctalus leisleri) at two sites in southern Britain. Journal of Zoology (London), 249: 173-180.

WeIDNER, H. 1995. Zur Hangplatzwahl der Breitflügelfledermaus Eptesicus serotinus (Schreber, 1774). Nyctalus, 5: 469-472.

Wickramasinghe, L. P., S. Harris, G. Jones, and N. Vaughan-Jennings. 2004. Abundance and Species Richness of Nocturnal Insects on Organic and Conventional Farms: Effects of Agricultural Intensification on Bat Foraging. Conservation Biology, 18: 1283-1292. 
Table 1: Joint effects of the major variables of interest and influence of the size of the buffer. Corine Land Cover habitat typology H231: Pastures, H242: Heterogeneous agricultural areas, $\mathrm{H} 243$ : Land principally occupied by agriculture, with significant areas of natural vegetation

\begin{tabular}{|l|l|l|l|l|l|}
\hline $\begin{array}{l}\text { Buffer } \\
\text { Size }\end{array}$ & $\mathrm{H} 231$ & $\mathrm{H} 242$ & $\mathrm{H} 243$ & $\begin{array}{l}\text { River } \\
\text { density }\end{array}$ & AIC \\
\hline 100 & $P=0.036$ & $P=0.027$ & $P=0.78$ & $P=0.27$ & 288.75 \\
\hline 250 & $P=0.007$ & $P=0.09$ & $P=0.63$ & $P=0.63$ & 287.15 \\
\hline 500 & $P<0.001$ & $P=0.029$ & $P=0.54$ & $P=0.47$ & 276.40 \\
\hline 750 & $P<0.001$ & $P=0.006$ & $P=0.32$ & $P=0.46$ & 266.19 \\
\hline 1000 & $P<0.001$ & $P=0.045$ & $P=0.66$ & $P=0.49$ & 261.69 \\
\hline 1250 & $P<0.001$ & $P=0.065$ & $P=0.85$ & $P=0.40$ & 266.25 \\
\hline 1500 & $P<0.001$ & $P=0.081$ & $P=0.76$ & $P=0.41$ & 262.1 \\
\hline 2000 & $P<0.001$ & $P=0.064$ & $P=0.42$ & $P=0.39$ & $\mathbf{2 5 5 . 4 3}$ \\
\hline 2500 & $P<0.001$ & $P=0.18$ & $P=0.89$ & $P=0.23$ & 263.73 \\
\hline 4000 & $P=0.005$ & $P=0.90$ & $P=0.62$ & $P=0.05$ & 269.79 \\
\hline 6000 & $P=0.004$ & $P=0.94$ & $P=0.37$ & $P=0.037$ & 269.92 \\
\hline 8000 & $P=0.006$ & $P=0.89$ & $P=0.16$ & $P=0.005$ & 270.45 \\
\hline
\end{tabular}


Figure 1: Geographical location of the study area (Cher), land cover use in the Cher region
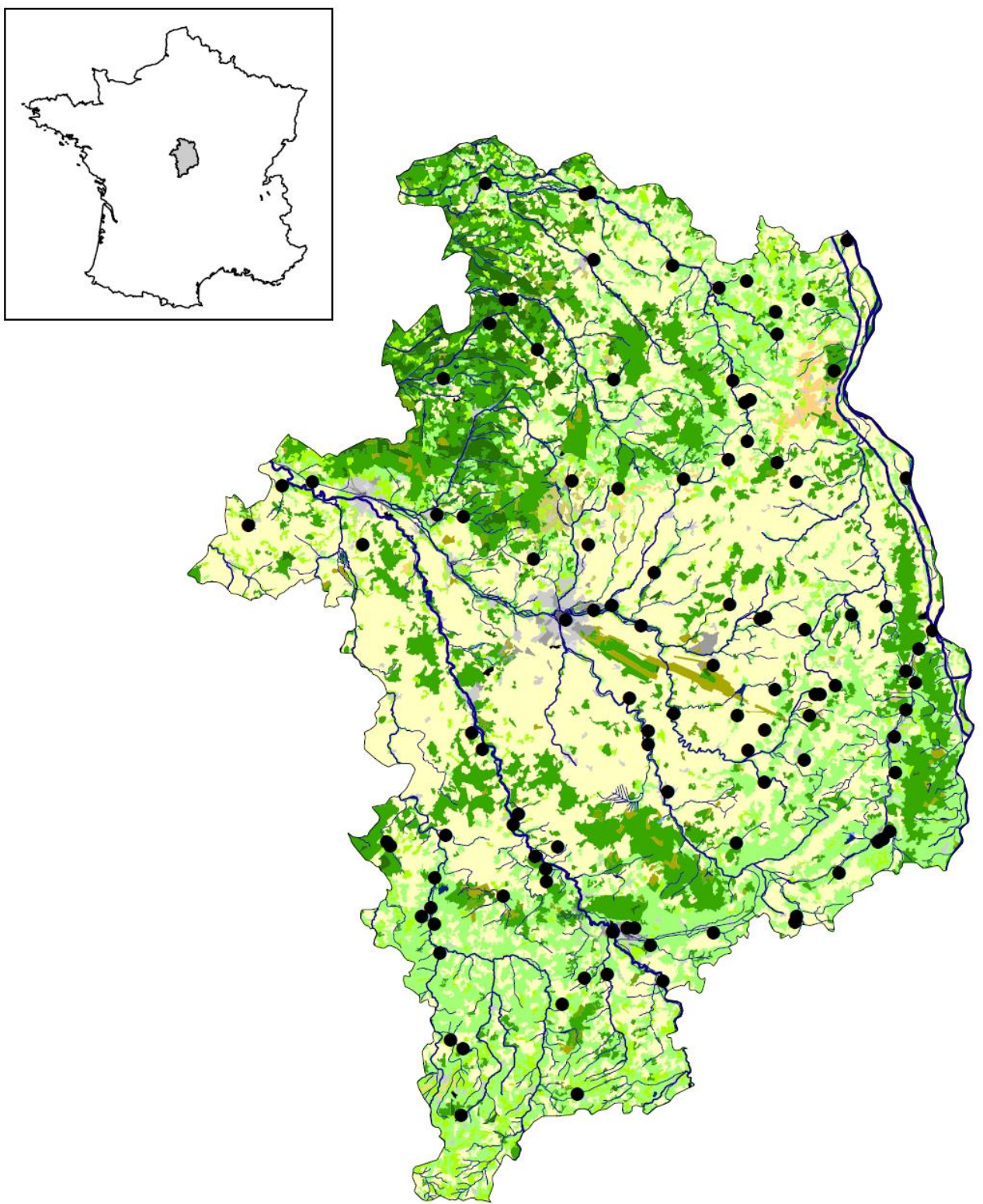

Land cover and land use classes according to CORINE Land Cover habitat classification

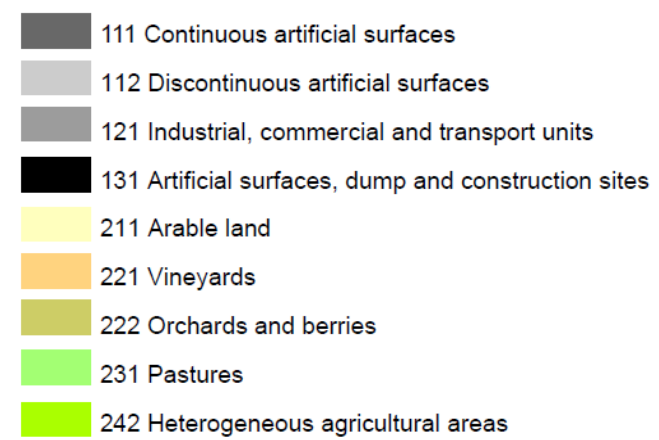

243 Agriculture, with areas of natural vegetation
311 Broad-leaved forest
312 Coniferous forest
313 Mixed forest
321 Natural grasslands
322 Scrub and heathland
324 Transitional woodland-shrub
511 Water courses
512 Bodies of water


Figure 2: Differences in a $2000 \mathrm{~m}$ habitat selection radius between Serotine bat roost and random points. Significant differences ( $P$-value $>0.05$, see also Supplementary material Appendix S3) are indicated with an asterisk (*). Corine Land Cover habitat typology: H111: Continuous artificial surfaces, H112: Discontinuous artificial surfaces, H121: Industrial, commercial and transport units, $\mathrm{H} 131$ : Artificial surfaces, dump and construction sites, $\mathrm{H} 211$ : Arable land, H221: Vineyards, H231: Pastures, H242: Heterogeneous agricultural areas, H243: Land principally occupied by agriculture, with significant areas of natural vegetation, H311: Broad-leaved forest, H312: Coniferous forest, H313: Mixed forest, H321: Natural grasslands, H322: Scrub and heathland, H324: Transitional woodland-shrub, H331: Open spaces with little or no vegetation, H511: Water courses, H512: Bodies of water.

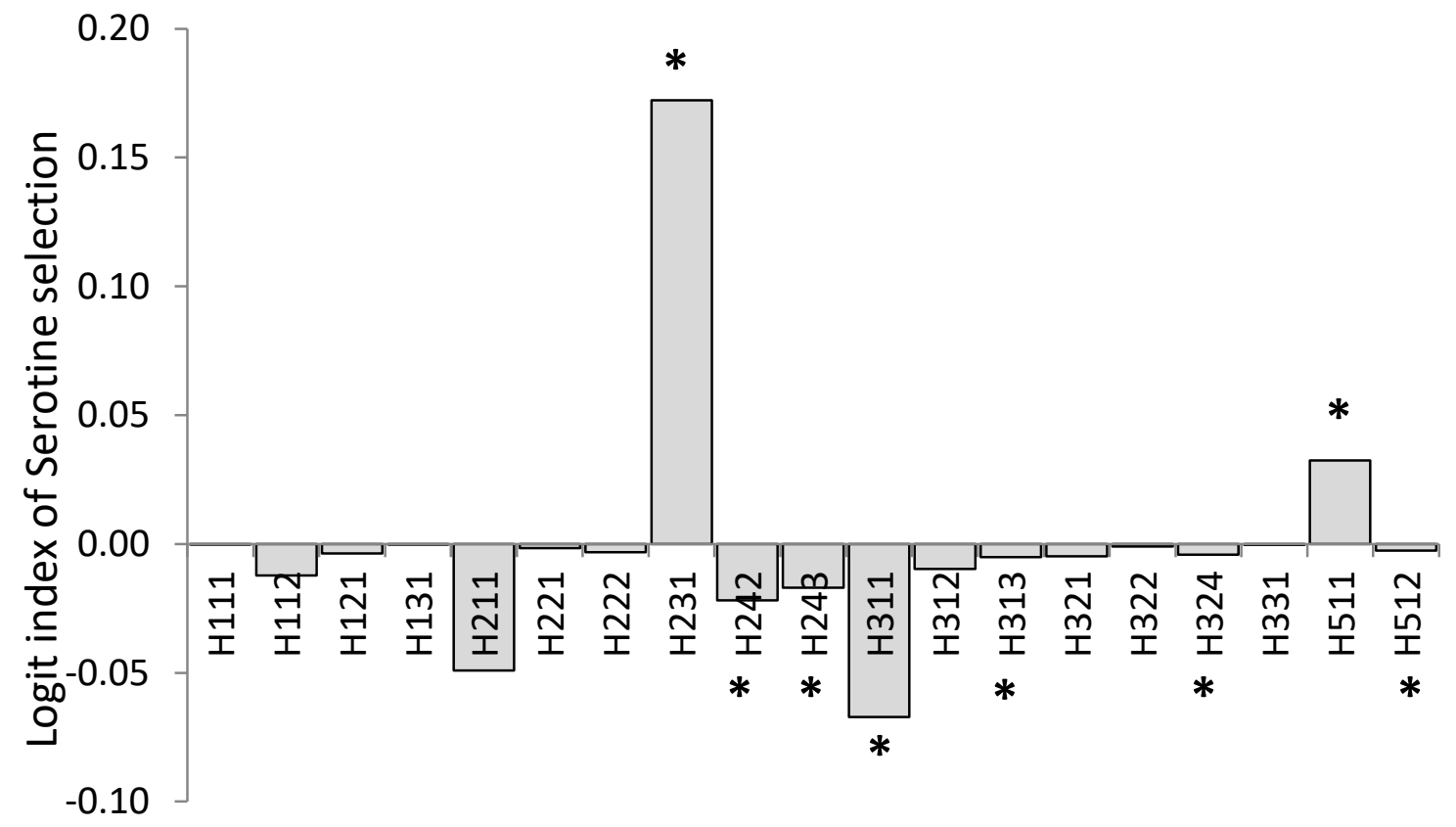


Figure 3: Identification of the most likely causal factors using hierarchical partitioning. Corine Land Cover habitat typology: H112: Discontinuous artificial surfaces, H121: Industrial, commercial and transport units, H211: Arable land, H221: Vineyards, H222: Orchards and berries, H231: Pastures, H311: Broad-leaved forest, H312: Coniferous forest, H511: Water courses.

842
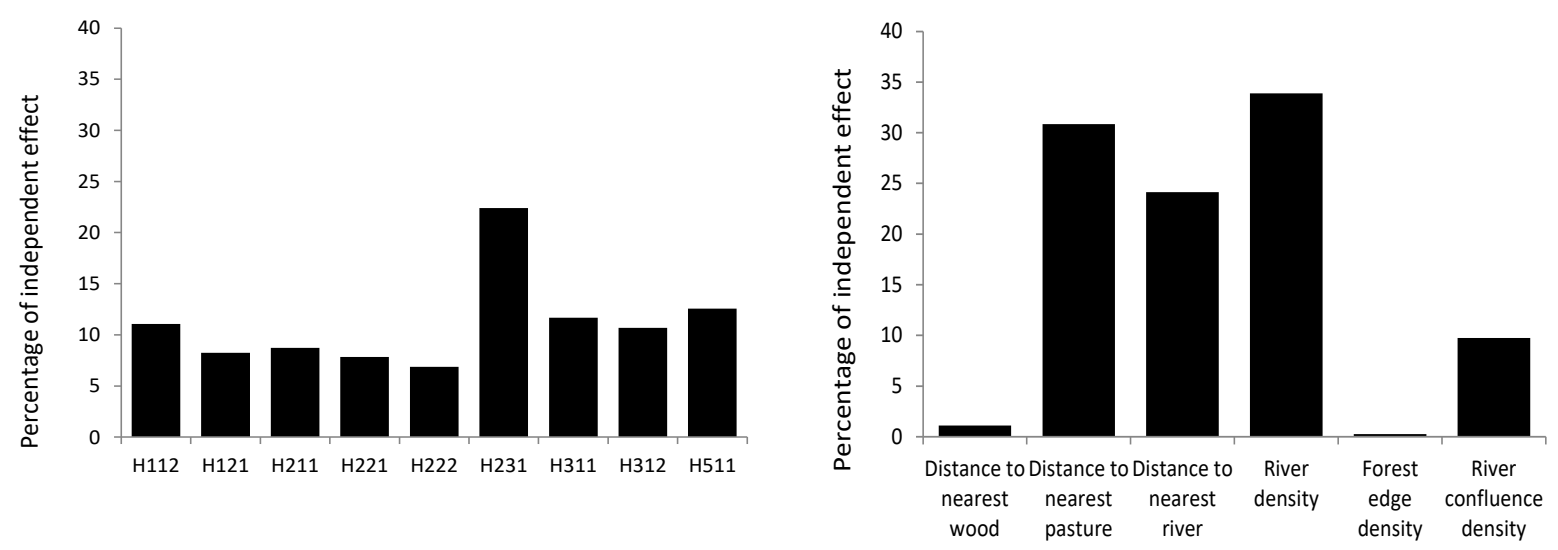


\section{Pipistrellus pipistrellus (B) and random point (C)}

A

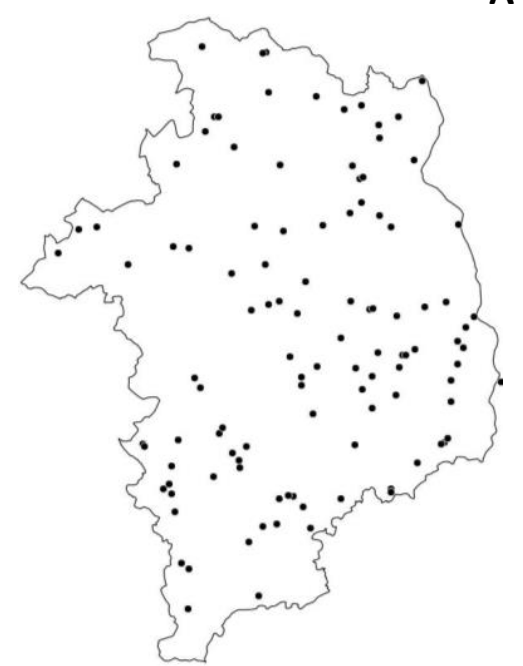

B

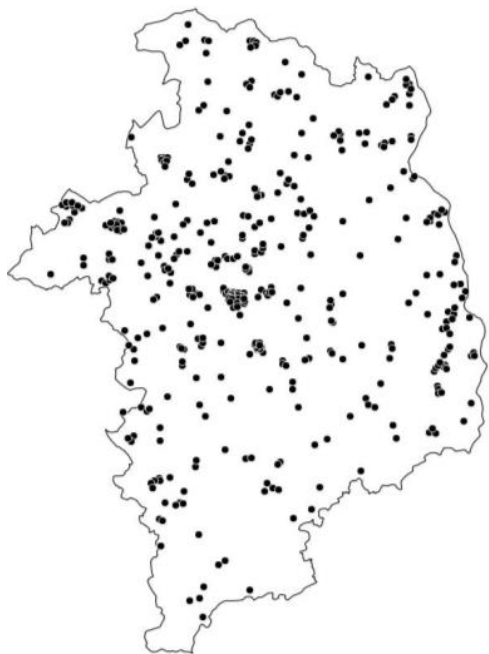

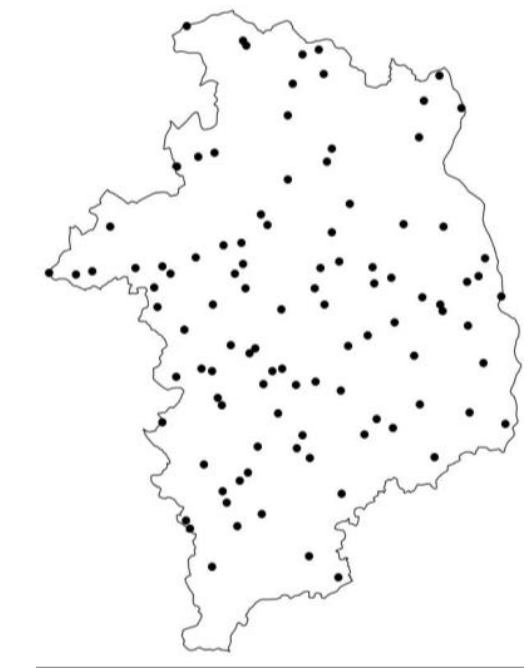


854

855

856

857

858

859

860

861

862

863

864

865

866

867

868

869

870

871

872

873

\section{Supplementary material - Appendix S2:}

Table S2: Table showing the correlations between habitat types (the area of each habitat type within a $2 \mathrm{~km} 2$ buffer size), as calculated by spearman's rank correlation. The important correlations between variables (correlation coefficient $\mid$ rho| $\geq 0.5$; Freckleton, 2002) are indicated in bold. Corine Land Cover habitat typology: H111: Continuous artificial surfaces, H112: Discontinuous artificial surfaces, H121: Industrial, commercial and transport units, 131: Artificial surfaces, dump and construction sites, H211: Arable land, H221: Vineyards, H222: Orchards and berries, H231: Pastures, H242: Heterogeneous agricultural areas, H243: Land principally occupied by agriculture, with significant areas of natural vegetation, $\mathrm{H} 311$ : Broad-leaved forest, H312: Coniferous forest, H313: Mixed forest, H321: Natural grasslands, H322: Scrub and heathland, H324: Transitional woodland-shrub, H331: Open spaces with little or no vegetation, H511: Water courses, H512: Bodies of water.

\begin{tabular}{|c|c|c|c|c|c|c|c|c|c|c|c|c|c|c|c|c|c|c|c|c|c|}
\hline & H111 & $\mathrm{H} 112$ & H121 & H131 & H141 & H142 & $\mathrm{H} 211$ & $\mathrm{H} 221$ & $\mathrm{H} 222$ & H231 & $\mathrm{H} 242$ & $\mathrm{H} 243$ & H311 & H312 & H313 & H321 & H322 & H324 & H331 & H511 & $\mathrm{H} 512$ \\
\hline H111 & & 0,18 & $-0,03$ & $-0,01$ & $-0,01$ & 0,50 & 0,04 & $-0,02$ & $-0,02$ & 0,03 & 0,03 & $-0,09$ & $-0,08$ & $-0,03$ & $-0,03$ & $-0,02$ & $-0,01$ & $-0,04$ & $-0,01$ & $-0,02$ & $-0,03$ \\
\hline $\mathrm{H} 112$ & & & 0,41 & 0,16 & 0,18 & 0,33 & 0,11 & $-0,05$ & 0,05 & $-0,08$ & 0,17 & 0,15 & $-0,17$ & $-0,01$ & $-0,02$ & 0,03 & 0,11 & $-0,18$ & 0,16 & 0,08 & 0,02 \\
\hline $\mathrm{H} 121$ & & & & $-0,03$ & 0,37 & 0,33 & $-0,12$ & $-0,06$ & 0,18 & $-0,11$ & 0,08 & 0,12 & 0,02 & 0,01 & $-0,10$ & 0,14 & $-0,04$ & $-0,11$ & $-0,03$ & 0,14 & 0,26 \\
\hline $\mathrm{H} 141$ & & & & & & 0,51 & $-0,12$ & $-0,02$ & $-0,02$ & $-0,14$ & $-0,10$ & $-0,09$ & $-0,07$ & $-0,03$ & $-0,03$ & 0,50 & $-0,01$ & $-0,04$ & $-0,01$ & $-0,02$ & 0,27 \\
\hline $\mathrm{H} 142$ & & & & & & & $-0,14$ & $-0,04$ & $-0,04$ & 0,05 & 0,00 & 0,00 & $-0,02$ & $-0,07$ & $-0,07$ & 0,23 & $-0,03$ & $-0,08$ & $-0,02$ & $-0,04$ & 0,09 \\
\hline H211 & & & & & & & & 0,00 & $-0,26$ & $-0,51$ & 0,11 & $-0,21$ & $-0,47$ & $-0,46$ & $-0,19$ & $-0,01$ & 0,09 & $-0,28$ & 0,04 & $-0,07$ & $-0,37$ \\
\hline H221 & & & & & & & & & $-0,04$ & $-0,01$ & 0,09 & $-0,09$ & $-0,01$ & $-0,07$ & $-0,07$ & $-0,04$ & $-0,03$ & $-0,08$ & $-0,02$ & $-0,04$ & $-0,07$ \\
\hline $\mathrm{H} 242$ & & & & & & & & & & & & 0,16 & $-0,16$ & $-0,20$ & $-0,14$ & $-0,14$ & 0,11 & $-0,20$ & $-0,10$ & 0,10 & $-0,05$ \\
\hline $\mathrm{H} 243$ & & & & & & & & & & & & & $-0,06$ & 0,06 & $-0,08$ & $-0,02$ & $-0,04$ & $-0,14$ & 0,06 & 0,25 & $-0,02$ \\
\hline H311 & & & & & & & & & & & & & & 0,38 & 0,14 & $-0,06$ & $-0,07$ & 0,27 & 0,02 & $-0,09$ & 0,18 \\
\hline H312 & & & & & & & & & & & & & & & 0,23 & 0,09 & $-0,05$ & 0,14 & $-0,03$ & $-0,07$ & 0,28 \\
\hline H313 & & & & & & & & & & & & & & & & $-0,07$ & $-0,05$ & 0,44 & $-0,03$ & 0,09 & $-0,01$ \\
\hline H321 & & & & & & & & & & & & & & & & & $-0,03$ & $-0,08$ & $-0,02$ & $-0,04$ & 0,08 \\
\hline H322 & & & & & & & & & & & & & & & & & & 0,17 & $-0,01$ & $-0,03$ & $-0,05$ \\
\hline
\end{tabular}

\section{Literature cited}

Freckleton, R.P. 2002. On the misuse of residuals in ecology: regression of residuals vs. multiple regression. Journal of Animal Ecology 71: 542-545. 
874 Supplementary material - Appendix S3:

875 Figure $\mathbf{S 1}$ : The cumulative number of serotine breeding colonies inventoried in the study 876 area (the Cher).

877

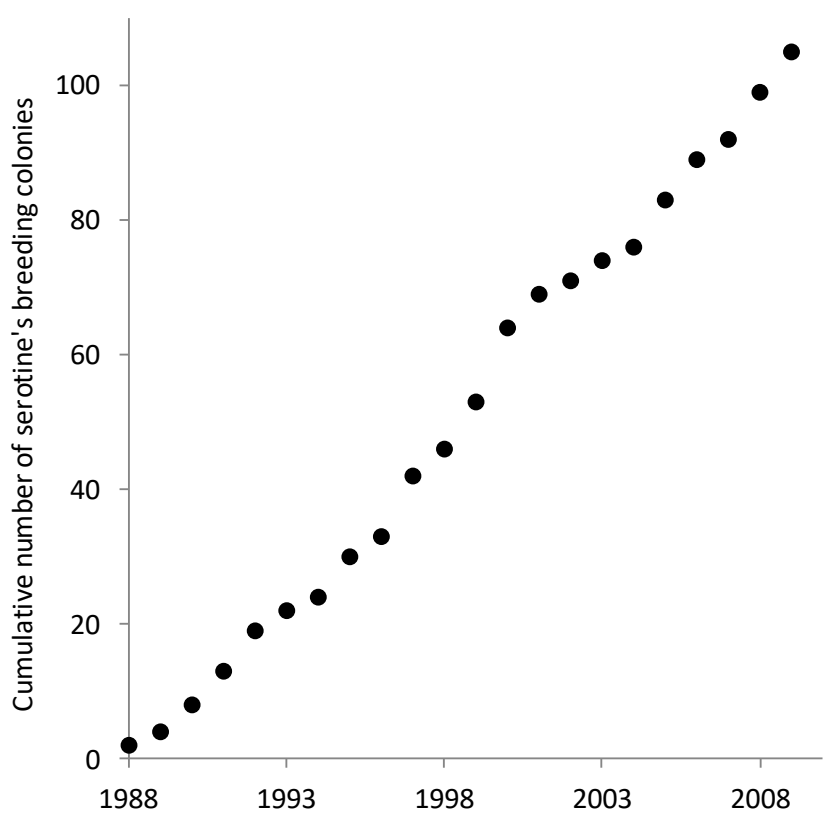


Supplementary material - Appendix S4:

Table S3-1: Differences in the habitat selection of serotine bats compared to random points in a buffer zone of $2000 \mathrm{~m}$. Corine Land Cover habitat typology: H111: Continuous artificial surfaces, H112: Discontinuous artificial surfaces, H121: Industrial, commercial and transport units, H131: Artificial surfaces, dump and construction sites, H211: Arable land, H222: Orchards and berries, H221: Vineyards, H231: Pastures, H242: Heterogeneous agricultural areas, H243: Land principally occupied by agriculture, with significant areas of natural vegetation, H311: Broad-leaved forest, H312: Coniferous forest, H313: Mixed forest, H321: Natural grasslands, H322: Scrub and heathland, H324: Transitional woodland-shrub, H331: Open spaces with little or no vegetation, H511: Water courses, H512: Bodies of water.

\begin{tabular}{|c|c|c|c|}
\hline Habitat & Estimate & F value & $P$ value \\
\hline $\mathrm{H} 111$ & $\beta=-5.498 \pm 14.908 \mathrm{SE}$ & $F=0.136$ & $P=0.71$ \\
\hline $\mathrm{H} 112$ & $\beta=-1.466 \pm 0.768 \mathrm{SE}$ & $F=3.644$ & $P=0.06$ \\
\hline $\mathrm{H} 121$ & $\beta=-1.658 \pm 1.502 \mathrm{SE}$ & $F=1.218$ & $P=0.27$ \\
\hline $\mathrm{H} 131$ & $\beta=-66.717 \pm 94.342 \mathrm{SE}$ & $F=0.784$ & $P=0.38$ \\
\hline $\mathrm{H} 211$ & $\beta=-0.395 \pm 0.389 \mathrm{SE}$ & $F=1.046$ & $P=0.31$ \\
\hline $\mathrm{H} 221$ & $\beta=15.762 \pm 17.972 \mathrm{SE}$ & $F=1.216$ & $P=0.27$ \\
\hline $\mathrm{H} 222$ & $\beta=-2.947 \pm 4.689 \mathrm{SE}$ & $F=0.462$ & $P=0.50$ \\
\hline H231 & $\beta=1.489 \pm 0.439 \mathrm{SE}$ & $F=12.563$ & $P<0.001$ \\
\hline H242 & $\beta=-68.817 \pm 17.953$ SE & $F=46.178$ & $P<0.001$ \\
\hline H243 & $\beta=-77.409 \pm 25.731$ SE & $F=41.286$ & $P<0.001$ \\
\hline H311 & $\beta=-31.688 \pm 20.523$ SE & $F=7.607$ & $P=0.006$ \\
\hline H312 & $\beta=-0.955 \pm 0.567 \mathrm{SE}$ & $F=3.016$ & $P=0.08$ \\
\hline H313 & $\beta=93.656 \pm 58.122 \mathrm{SE}$ & $F=7.655$ & $P=0.005$ \\
\hline H321 & $\beta=-65.296 \pm 55.577 \mathrm{SE}$ & $F=3.794$ & $P=0.05$ \\
\hline H322 & $\beta=-134.422 \pm 300.1567 \mathrm{SE}$ & $F=2.484$ & $P=0.12$ \\
\hline H324 & $\beta=-125.700 \pm 81.973$ SE & $F=10.925$ & $P<0.001$ \\
\hline H331 & $\beta=-88.202 \pm 141.445 \mathrm{SE}$ & $F=1.249$ & $P=0.264$ \\
\hline H511 & $\beta=-4.193 \pm 3.294 \mathrm{SE}$ & $F=4.884$ & $P=0.027$ \\
\hline H512 & $\beta=-89.017 \pm 45.101$ SE & $F=7.866$ & $P=0.005$ \\
\hline
\end{tabular}

897

898

899 900

Table S3-2 : Differences between serotine bats compared to random points for the selection of the linear elements of landscape or distance to habitat, in a buffer zone of $2000 \mathrm{~m}$.

\begin{tabular}{|c|c|c|c|}
\hline Habitat & Estimate & F value & $P$ value \\
\hline Distance to nearest wood & $\beta=0.141 \pm 0.062 \mathrm{SE}$ & $F=5.4928$ & $P=0.019$ \\
\hline Distance to nearest pasture & $\beta=-0.183 \pm 0.053 \mathrm{SE}$ & $F=12.821$ & $P<0.001$ \\
\hline Distance to nearest river & $\beta=-0.498 \pm 0.125 \mathrm{SE}$ & $F=19.277$ & $P<0.001$ \\
\hline River density & $\beta=0.741 \pm 0.212 \mathrm{SE}$ & $F=38.387$ & $P<0.001$ \\
\hline River confluence density & $\beta=0.820 \pm 0.224 \mathrm{SE}$ & $F=14.825$ & $P<0.001$ \\
\hline Forest edge density & $\beta=0.031 \pm 0.043 \mathrm{SE}$ & $F=0.723$ & $P=0.469$ \\
\hline
\end{tabular}

Figure S3: Boxplot of the differences between serotine bats (1) compared to random points (0) 
for the selection of the linear elements of landscape or distance to habitat, in a buffer zone of $2000 \mathrm{~m}$.

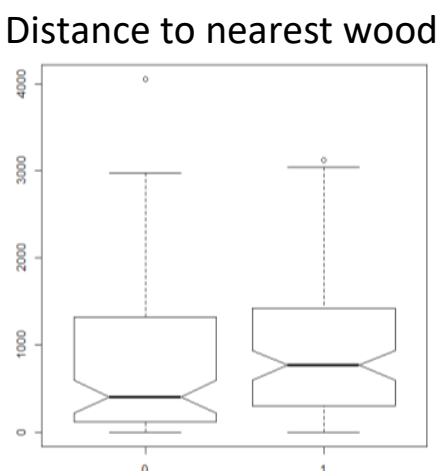

River density

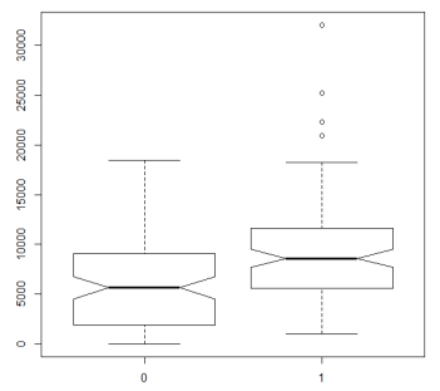

Distance to nearest pasture

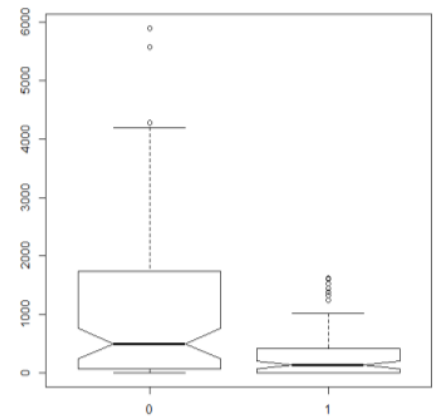

River confluence density

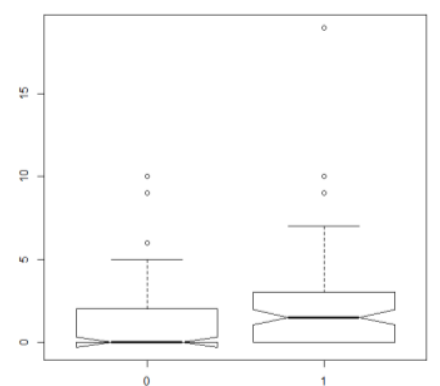

Distance to nearest river

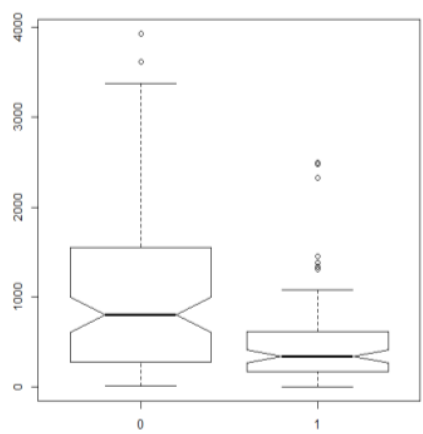

Forest edge density

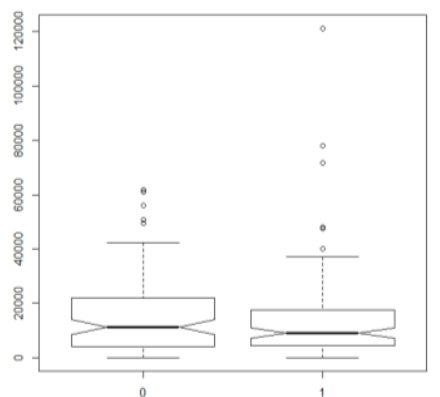


909 Figure S4: Differences in a $2000 \mathrm{~m}$ habitat selection radius between Serotine bat roost and pipistrelle roosts. Significant differences (P-value $>0.05)$ are indicated with an asterisk $(*)$.

911 Corine Land Cover habitat typology: H111: Continuous artificial surfaces, H112:

912 Discontinuous artificial surfaces, H121: Industrial, commercial and transport units, H131: Artificial surfaces, dump and construction sites, H211: Arable land, H221: Vineyards, H231: Pastures, H242: Heterogeneous agricultural areas, H243: Land principally occupied by agriculture, with significant areas of natural vegetation, H311: Broad-leaved forest, H312: Coniferous forest, H313: Mixed forest, H321: Natural grasslands, H322: Scrub and heathland, H324: Transitional woodland-shrub, H331: Open spaces with little or no vegetation, H511: Water courses, H512: Bodies of water. 